\title{
PENGARUH FOREIGN DIRECT INVESTMENT DAN AFTA TERHADAP KESEMPATAN KERJA SEKTORAL DI ASEAN 5
}

\author{
Ilhamdi $^{1}$, Rina Oktaviani ${ }^{2}$, Yeti Lis Purnamadewi ${ }^{2}$ \\ ${ }^{1}$ Mahasiswa Magister Program Studi Ilmu Ekonomi, FEM IPB \\ ${ }^{2}$ Staf Pengajar FEM IPB \\ Artikel diterima Juni 2015 \\ Artikel disetujui untuk dipublikasikan Desember 2015
}

\begin{abstract}
This study aims to analyze the impact of Foreign Direct Investment (FDI) and ASEAN Free Trade Agreement (AFTA) on sectoral employment in ASEAN 5. The analysis focused on five main sectors, namely agriculture, mining, manufacturing, construction and service sectors. This paper uses panel data approach with Fixed Effect Model. Variable used include employment as an edogenous variable, while GDP, wages and AFTA as exogenous variables. Cross section data that are used in this study consist of ASEAN 5 countries, namely Indonesia, Malaysia, Philippines, Thailand and Vietnam with periods of observation as much as 9 years, from 2006 until 2014.The result of this paper that FDI, GDP, wages and AFTA have different impacts in each sector. FDI has positive impact on employment in service sector. GDP has positive impact on employment in manufacturing, construction and service sectors. While GDP in the agricultural and mining sectors has negative impact on employment. The wage has a positive impact on employment in the mining and agricultural sectors. ASEAN Free Trade Agreement (AFTA) that took place in 2010 has a positive impact on employment in the manufacturing and mining sectors.Foreign Direct Investment is one factor to overcome employment issues in ASEAN 5, especially in service sector. While GDP becomes an important variable in enhancing ASEAN 5 employment in the manufacturing, construction and services. Increasing wages can be applied on agriculture and mining as it has a positive impact on employment. AFTA that has taken place is proper policy for the ASEAN 5 to encourage economic growth in the mining and manufacturing sectors that have an impact on increasing demand of labor in the sector.
\end{abstract}

Keywords: FDI, AFTA, employment, panel data

\section{PENDAHULUAN}

\section{Latar Belakang}

Akhir tahun 2015 merupakan awal diberlakukannya Masyarakat Ekonomi ASEAN (MEA). MEA merupakan peluang bagi negara-negara anggota untuk memperkuat perekonomiannya dalam menghadapi persaingan global. Terdapat empat pilar yang dapat memperkuat perekonomian melalui kerjasama tersebut. Pertama, menjadikan ASEAN sebagai satu entitas pasar sehingga persoalan bea cukai, standarisasi tenaga kerja, dan investasi antar negara menjadi lebih mudah. Kedua, meningkatkan daya saing produk yang di jual di dalam 
pasar tersebut untuk meningkatkan kualitas produk tersebut. Ketiga, menghapus kesenjangan yang berlebihan antar negara-negara ASEAN agar tercapai kesejahteraan yang merata. Keempat, menjadikan kawasan ASEAN terintegrasi secara penuh ke dalam perekonomian global.

Masyarakat Ekonomi ASEAN (MEA) merupakan kelanjutan dari rangkaian kerjasama-kerjasama regional yang dimulai dengan terbentuknya ASEAN pada 8 Agustus 1967. Dari sisi ekonomi, tujuan utama dari kerjasama tersebut mempercepat pertumbuhan ekonomi masyarakat bangsa-bangsa Asia Tenggara, perluasan perdagangan dan pengkajian masalah-masalah komoditas internasional. Selanjutnya, pada Konferensi Tingkat Tinggi (KTT) ASEAN ke IV di Singapura tahun 1992 dibentuklah ASEAN Free Trade Area (AFTA) untuk membentuk kawasan bebas perdagangan dalam rangka meningkatkan daya saing ekonomikawasan regional dengan menjadikan ASEAN sebagai basis produksi dunia, menarik lebih banyak investasi asing langsung (Foreign Direct Investment /FDI) dan meningkatkan perdagangan antar negara anggota ASEAN (intraASEAN Trade).

Untuk mewujudkan tujuan AFTA tersebut, maka dibuatlah skema Common Effective Preferential Tariffs For ASEAN Free Trade Area (CEPTAFTA). Skema tersebut dengan penurunan tarif hingga menjadi $0-5 \%$, penghapusan pembatasan kuantitatif dan hambatan-hambatan non tariff lainnya. Pada tahun 2010 terjadi kesepakatan untuk menghapus bea masuk impor barang bagi Brunei Darussalam, Filipina, Indonesia, Malaysia, Singapura dan Thailand. Sedangkan Kamboja, Laos, Myanmar dan Vietnam pembebasan tarif tersebut berlaku pada tahun 2015 .

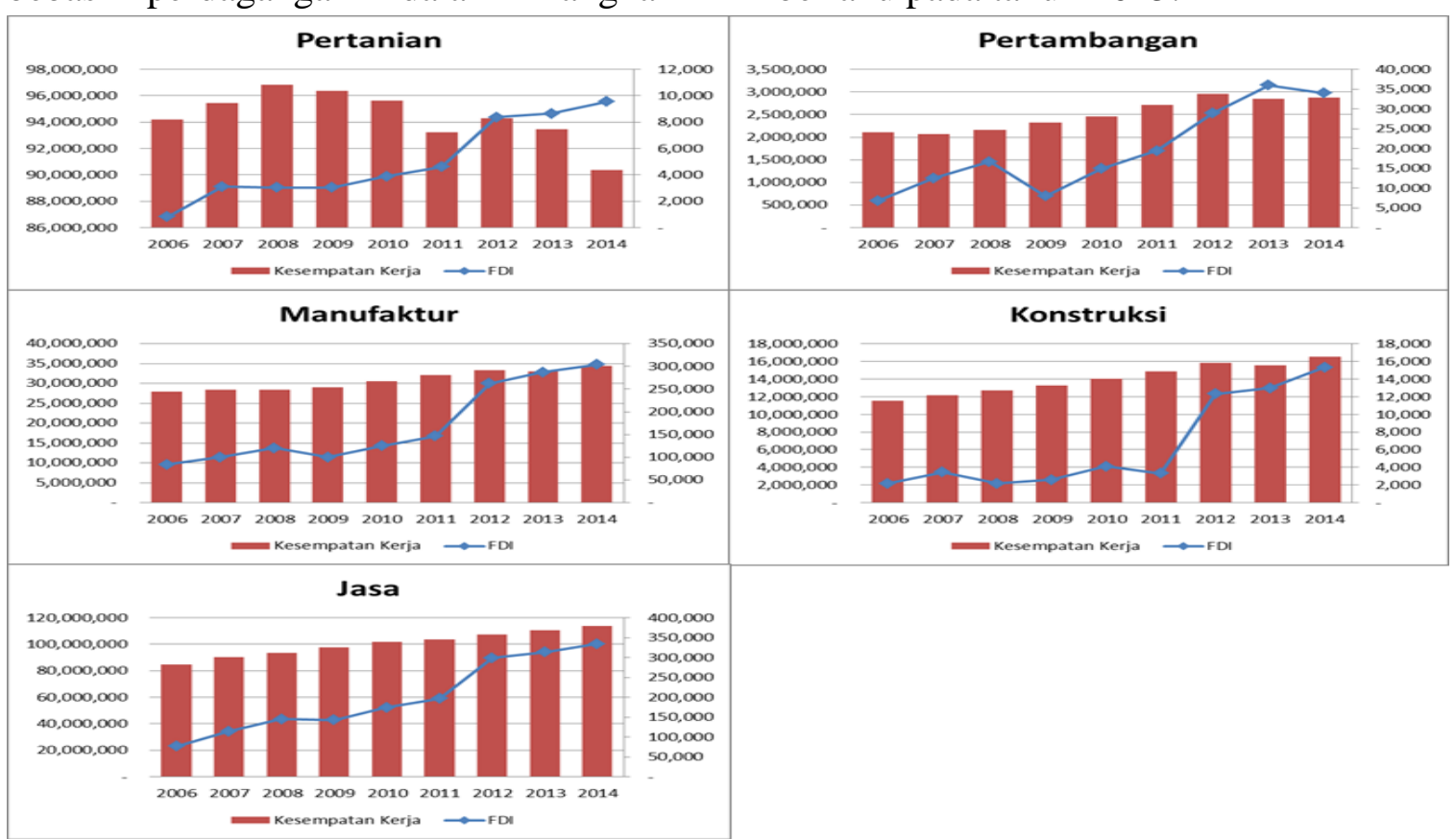

Sumber: Lembaga statistik masing-masing negara ASEAN 5

Gambar 1. FDI stock (dalam juta dolar AS) dan kesempatan kerja sektoral di ASEAN 5 periode 2006-2014 
Waldkirch

mengungkapkan bahwa permulaan kerja sama perdagangan bebas kawasan Amerika Utara atau North American Free Trade Agreement (NAFTA) memberikan dampak signifikan atas masuknya aliran Foreign Direct Investment ke negara Meksiko. Hal ini juga terlihat pada Gambar 1 yang menunjukkan bahwa kerjasama AFTA yang berlangsung tahun 2010 memberikan kenaikan FDI secara signifikan di negara ASEAN 5 (Filipina, Indonesia, Malaysia, Thailand dan Vietnam) di bandingkan periode sebelum berlangsungnya kerjasama tersebut. FDI terserap pada lima sektor ekonomi utama yaitu pertanian, pertambangan, manufaktur, konstruksi dan jasa.

Banyak perdebatan mengenai dampak yang ditimbulkan dari FDI terhadap perekonomian (termasuk kesempatan kerja) di host country. Onaran (2007), Aitken dan Harrison (1999) mengungkapkan bahwa FDI memiliki dampak negatif terhadap kesempatan kerja domestik host country. Sementara Radosevic (2000) menemukan dampak positif yang ditimbulkan FDI terhadap kesempatan kerja di negara yang telah siap melakukan transisi dan kesiapan tenaga kerja domestik yang produktif.

Alfaro (2003) meneliti FDI yang masuk pada sektor primer, manufaktur dan jasa di negara-negara OECD. FDI yang masuk pada sektor primer seperti pertanian dan pertambangan memberikan dampak negatif terhadap perekonomian. Sementara FDI yang masuk pada sektor manufaktur memiliki dampak positif terhadap pertumbuhan ekonomi masing-masing negara. Namun pada sektor jasa memberikan dampak yang ambigu terhadap pertumbuhan ekonomi.
Jude dan Silaghi (2015) dengan menggunakan teori permintaan tenaga kerja di negara CEECs (Central and Eastern European Coutntries). FDI memberikan dampak negatif terhadap kesempatan kerja di negara CEECs. Hal ini disebabkan oleh persaingan ketat antar perusahaan domestik dan perusahaan asing yang masuk melalui FDI. Determinan lain seperti PDB memberikan dampak positif terhadap kesempatan kerja, sementara tingkat upah tidak berpengaruh signifikat terhadap kesempatan kerja.

Sementara Konings (2004), Jude dan Silaghi (2015) selain menggunakan FDI juga memasukkan variabel dummy berupa perdagangan bebas. Hasil studi mengungkapkan bahwa kerjasama perdagangan bebas di suatu kawasan tidak memiliki dampak terhadap kesempatan kerja di host country.

Berdasarkan uraian di atas menimbulkan pertanyaan apakah FDI sektoral dan determinan permintaan tenaga kerja seperti PDB dan upah sektoral memberikan dampak terhadap pertumbuhan kesempatan kerja sektoral di ASEAN 5. Dan bagaimana kerjasama kerjasama perdagangan bebas AFTA memberikan dampak signifikan terhadap kesempatan kerja sektoral di ASEAN 5.

\section{TINJAUAN PUSTAKA}

\section{Dampak FDI terhadap Kesempatan Kerja}

Foreign Direct Investment (FDI) sebagai salah satu bentuk investasi atau akumulasi modal dapat mendorong peningkatan pertumbuhan ekonomi yang bermuara pada peningkatan permintaan tenaga kerja. Investasi merupakan pembelanjaan penanaman modal seperti perlengkapanperlengkapan produksi untuk 
meningkatkan kapasitas produksi barang dan jasa.

Kenaikan investasi akan berdampak pada peningkatan output jika nilai investasi lebih dari nilai depresiasinya. Kenaikan output akan meningkatkan beberapa input produksi salah satunya adalah permintaan tenaga kerja. Dalam hal ini maka permintaan tenaga kerja yang merupakan derived demand dari output dipengaruhi investasi secara tidak langsung.

Menurut Smith (2003) FDI dapat mempengaruhi tingkat efisiensi dalam produksi yang menyebabkan hubungan antara kesempatan kerja bisa memiliki dua arah yaitu positif dan negatif. Jika FDI yang masuk pada sektor-sektor ekonomi yang padat karya maka akan berdampak positif terhadap kesempatan kerja. Sementara jika FDI masuk pada sektor-sektor padat modal maka berdampak negatif terhadap kesempatan kerja.

\section{Dampak PDB terhadap Kesempatan Kerja Sektoral}

Pertumbuhan ekonomi mengacu pada peningkatan (output) barang dan jasa yang diproduksi oleh sistem perekonomian sepanjang waktu. Hal tersebut menyebabkan meningkatnya permintaan faktor produksi seperti tenaga kerja.

Namun, peningkatan output tidak selamanya dapat meningkatkan lapangan kerja baru. Ada perbedaan komposisi antara sektor padat modal dan padat karya. Pada perusahaan yang padat karya yang masih bersifat tradisional dan belum mengalami perubahan teknologi produksinya, memungkinkan menyerap lebih banyak tenaga kerja untuk meningkatkan output produksinya. Ini dikarenakan untuk menggunakan teknologi yang lebih canggih agar lebih efisien, dibutuhkan kapital baru yang jumlahnya tidak sedikit. Biasanya perusahaanperusahaan seperti ini merupakan perusahaan lokal di negara-negara berkembang.

Pada sektor yang sifatnya padat modal, perusahaan tersebut telah menerapkan teknologi yang canggih. Perusahaan yang berskala internasional biasanya berasal dari negara-negara maju. Perusahaan tersebut telah lama melakukan inovasi-inovasi dalam pengembangan teknologi produksi, sehingga berjalannya waktu sanggup untuk menambah kapital dalam jumlah yang besar untuk menerapkan teknologi yang lebih efisien. Dampaknya terjadi pengurangan penggunaan tenaga kerja seperti dalam teori ekspansi output dalam jangka panjang. Investasi asing langsung (perusahaan multinasional) yang masuk ke host country membawa teknologi canggih untuk memproduksi output. Sehingga keberadaannya tidak terlalu berdampak signifikan pada penciptaan lapangan kerja baru, bahkan akan menjadi ancaman bagi keberadaan perusahaan domestik.

\section{Dampak Upah Terhadap Kesempatan Kerja Sektoral}

Permintaan tenaga kerja merupakan hubungan antara tingkat upah dan jumlah pekerja yang dipekerjakan perusahaan pada jangka waktu tertentu. Dalam Binger dan Hoffman (1988), teori permintaan tenaga kerja merupakan pengembangan dari permintaan satu input variabel jangka pendek. Permintaan akan input berasal dari permintaan output. Sementara penawaran tenaga kerja sebagai fungsi dari tingkat upah merupakan turunan dari utilitas.

Jika dalam perekonomian terjadi peningkatan penawaran tenaga kerja maka akan terjadi penurunan tingkat 
upah, maka jumlah permintaan tenaga kerja akan meningkat. Di negaranegara dengan angkatan kerja atau dengan tingkat pengangguran yang tinggi akan menyebabkan penurunan tingkat upah. Hal ini menjadi keuntungan bagi perusahaan dengan menambah jumlah tenaga kerja untuk meningkatkan produksi output. Dalam hal ini menunjukkan bahwa tingkat upah sektoral merupakan determinan bagi kesempatan kerja sektoral di suatu negara.

\section{Dampak AFTA terhadap Kesempatan Kerja Sektoral}

ASEAN Free Trade Agreement merupakan kerjasama perdagangan antar negara-negara ASEAN guna meningkatkan daya saing ekonomikawasan regional. Berdasarkan teori Heckscher-Ohlin perdagangan terjadi karena adanya perbedaan limpahan sumber daya antara negara. Kerjasama tersebut meningkatkan volume perdagangan sektoral yang berdampak pada meningkatnya kesempatan kerja sektoral. Selain itu kerjasama perdagangan juga merupakan strategi negara-negata berkembang dalam menghadapi globalisasi ekonomi.

Rama dalam Jenkins (2006) menyebutkan bahwa terdapat dua alur dampak globalisasi terhadap kesempatan kerja. Salah satu yang paling penting dengan meningkatkan perdagangan, Foreign Direct Investment (FDI) dan transfer teknologi. Saat ini banyak terbentuk blok-blok perdagangan sebagai respon dari globalisasi. Salah satunya di Asia Tenggara dengan ASEAN Free Trade Agreement (AFTA).

Kerjasama tersebut diharapkan dapat meningkatkan perdagangan antar negara-negara ASEAN serta memungkinkan masuknya investor asing untuk mengembangkan pasarnya di kawasan Asia Tenggara. Besarnya potensi pasar di kawasan tersebut dimanfaatkan perusahaan multinasional dengan mendirikan industri baru maupun membuat anak perusahaan di negara tujuan.

Ada dua tujuan perusahaan multinasional masuk ke negara tujuan investasi. Pertama, ingin menjadikan negara tujuan tersebut sebagai basis produksi bagi pasar global. Dikarenakan dekatnya dengan bahan mentah maupun bahan baku, serta rendahnya tingkat upah dibandingkan negara asal investor. Kedua, ingin melebarkan pasar ke negara tujuan yang memiliki potensi besar untuk berkembang. Dengan tujuan tersebut memiliki dua dampak yang berbeda-beda terhadap kesempatan kerja.

\section{Penelitian Terdahulu}

$\begin{array}{ccc}\text { Banyak } & \text { penelitian mengenai } \\ \text { dampak } & \text { globalisasi } & \text { terhadap }\end{array}$ kesempatan kerja yang fokus pada perdagangan internasional. Kemudian berkembang dengan memasukkan peran FDI sebagai pendorong perubahan struktur tenaga kerja di host country. Sudah menjadi pendapat umum bahwa FDI bisa memberikan keuntungan bagi host country. Selain investasi dalam bentuk keuangan, FDI dapat memberikan sumber daya lainnya berupa teknologi, transfer pengetahuan ke perusahaan lokal, sehingga dapat mendongkrak perekonomian negara tersebut.

Jenkins (2006) mengungkapkan penelitiannya bahwa meskipun cepatnya pertumbuhan FDI di Vietnam selama 1990-an dan porsi yang signifikan dari afiliasi asing terhadap output industri dan ekspor pada awal abad 21. Namun, dampak langsung terhadap tenaga kerja sangat terbatas. Sebagian besar tenaga 
kerja terus bertahan pada sektor pertanian, jasa, perdagangan grosir dan eceran serta jasa transportasi. Sementara sektor tersebut termasuk yang minim dimasuki FDI. Bahkan ekspansi terbaru dari perusahaan asing pada sektor industri manufaktur tidak memiliki dampak besar terhadap kesempatan kerja. FDI pada sektor tersebut melalui greenfield investment hanya menciptakan lapangan kerja seperempat juta dari kebutuhan serapan tenaga kerja 1,3 juta sampai 1,4 juta jiwa tiap tahunnya. Selain itu banyak anak perusahaan asing yang masuk didominasi oleh industri padat modal, dan hanya $29 \%$ yang bersifat padat karya.

Jude dan Silaghi (2015) yang melakukan penelitian di Central and Eastern European Countries (CEECs) dengan menggunakan determinan kesempatan kerja berupa pertumbuhan output (PDB), tingkat upah dan FDI stock dengan menggunakan dua model estimasi fixed effect dan GMM estimation. Hasilnya menunjukkan bahwa pada model fixed effect, FDI tidak memiliki pengaruh signifikan terhadap kesempatan kerja, sementara pada model GMM memiliki pengaruh negatif terhadap kesempatan kerja. Sementara untuk FDI tahun sebelumnya memberikan dampak positif terhadap kesempatan kerja di dua model tersebut. Namun dengan menambahkan variabel dummy transisi ekonomi dan krisis ke dalam model, FDI memberikan dampak negatif terhadap kesempatan kerja untuk kedua model.

Transisi ekonomi dari negara post-communist ke negara terbuka memberikan dampak positif terhadap kesempatan kerja. Dampak negatif yang ditimbulkan oleh FDI dalam jangka pendek menunjukkan bahwa investasi yang masuk merupakan padat modal dan memiliki tingkat produktivitas lebih baik dibandingkan domestik, namun dalam jangka panjang investasi tersebut memberikan dampak positif terhadap kesempatan kerja. Sementara dalam periode transisi ekonomi tersebut pertumbuhan output di 20 negara CEECs memberikan dampak positif yang signifikan terhadap kesempatan kerja, sedangkan tingkat upah tidak memiliki pengaruh nyata terhadap kesempatan kerja di CEECs.

Penelitian Hunya dan Geishecker (2005) menyatakan bahwa FDI yang masuk ke host country dengan keuntungan efisiensi melakukan fragmentasi produksi di beberapa lokasi. Ketika investor asing menggantikan pemasok domestik dengan mengimpor input produksi, maka terjadi pengurangan kesempatan kerja di sektor hulu karena keberadaan importir. Mencinger (2003) mengungkapkan bahwa pada periode sembilan puluhan di negara-negara tersebut, perusahaan multinasional berkontribusi terhadap impor dibandingkan ekspor, dan hasil penelitian menunjukkan bahwa keduanya saling menggantikan. Sehingga secara keseluruhan dapat disimpulkan bahwa keterlibatan asing dalam perdagangan internasional tidak menyebabkan dampak yang signifikan terhadap kesempatan kerja.

Faktor domestik seperti tingkat upah dan output serta faktor internasional berupa ekspor, impor dan FDI menjadi determinan permintaan tenaga kerja dalam penelitian yang dilakukan Onaran (2007) di CEECs. Hasil penelitian menunjukkan bahwa integrasi ekonomi yang terjadi di Eropa melalui FDI dan perdagangan internasional memberikan dampak negatif terhadap kesempatan kerja. Bahkan proses transisi ekonomi menuju integrasi dengan perekonomian Eropa berdampak pada meningkatnya 
pengurangan tenaga kerja. Sementara faktor domestik seperti pertumbuhan output menjadi pendorong utama dalam meningkatkan kesempatan kerja dibandingkan FDI. Sementara tingkat upah tidak memiliki pengaruh signifikan terhadap kesempatan kerja.

Jenkins (2006) mengungkapkan bahwa FDI tidak berpengaruh nyata terhadap kesempatan kerja di Vietnam. Sementara pertumbuhan output memberikan dampak positif yang nyata terhadap kesempatan kerja di Vietnam pada saat transisi menuju perekonomian terbuka. Sementara tingkat upah memiliki dampak negatif terhadap kesempatan kerja di Vietnam. Sehingga kenaikan tingkat upah merupakan kebijakan kurang tepat bagi ketenagakerjaan di Vietnam.

\section{METODE PENELITIAN}

\section{Jenis dan Sumber Data}

Data yang digunakan adalah data panel, yang merupakan kombinasi data cross section dan data runtun waktu. Data panel dalam bentuk cross section merupakan negara-negara ASEAN 5 (Filipina, Indonesia, Malaysia, Thailand, dan Vietnam). Sedangkan data runtun waktu adalah data tahunan untuk periode 2006-2014.

Sumber data diperoleh dari pengumpulan data yang dilakukan dengan studi pustaka, berupa dokumen atau arsip yang di dapat dari UNCTADStat, ILOStat, World Bank, lembaga statistik masing-masing negara, situs internet, jurnal dan bukubuku terkait.

Data kesempatan kerja per sektor ekonomi berasal lembaga statistik masing-masing negara yang diterbitkan setiap tahunnya. Foreign Direct Investment (FDI) yang digunakan merupakan FDI stock (dolar AS) per sektor ekonomi yang diterbitkan juga oleh lembaga statistik masing-masing negara ASEAN 5. Sementara PDB riil (dolar AS) masingmasing negara per sektor diperoleh dari United Nations Conference on Trade and Development Investment (UNCTAD). Tingkat upah untuk negara ASEAN 5 diterbitkan oleh LABORSTA internet statistics di bawah naungan Internasional Labor Organization, serta lembaga statistik di masing-masing negara.

\section{Persamaan Model}

Model yang digunakan pada penelitian ini merupakan modifikasi dari penelitian-peneltian sebelumnya seperti Cristina Jude et al. (2015), Greenway et al. (1999), serta Jenkins (2006). Estimasi persamaan pengaruh FDI, pertumbuhan ekonomi, upah dan AFTA terhadap kesempatan kerja pada masing-masing sektor ekonomi di negara-negara ASEAN 5 adalah sebagai berikut:

$$
\begin{aligned}
\ln L_{i t}= & \lambda+\emptyset_{1} \ln F D I_{i t}+\emptyset_{2} \ln Y_{i t}+ \\
& \emptyset_{3} \ln W_{i t}+\emptyset_{4} D A F T A_{i t}+\varepsilon_{i t}
\end{aligned}
$$

dimana L adalah kesempatan kerja dalam satuan jiwa, FDI adalah investasi asing langsung riil dalam satuan dolar AS, Y adalah PDB riil dalam satuan dolar AS, $\mathrm{W}$ adalah tingkat upah riil dalam satuan dolar AS, dan DAFTA merupakan variabel dummy dimana sebelum berlangsungnya $\mathrm{AFTA}=0$ dan setelah $\mathrm{AFTA}=1$. Untuk $\emptyset_{k}$ merupakan koefisien yang diestimasi $(\mathrm{k}=1,2,3,4), \lambda$ sebagi intersep persamaan regresi, serta $\varepsilon$ sebagai error term. Sementara i mewakili cross section ASEAN 5 dan $\mathrm{t}$ periode waktu pengamatan. Untuk mempermudah hasil analisis maka seluruh data diubah ke dalam logaritma natural (Ln) kecuali variabel dummy AFTA. 


\section{Model Data Panel}

Studi ini bertujuan untuk mengetahui dampak FDI terhadap kesempatan kerja dengan ruang lingkup negara-negara ASEAN 5. Untuk menjawab permasalahan tersebut, maka studi ini menggunakan ekonometrika data panel. Data panel merupakan data yang diperoleh dari data cross section yang diobservasi berulang pada unit yang sama pada waktu yang berbeda. Data panel memiliki sifat yang robust terhadap tipe pelanggaran asumsi Gaus Markov yaitu heterokedastisitas dan normalitas.

Dalam ekonometrika data panel, ada tiga model pendekatan dalam estimasi yaitu common effect, fixed effect dan random effect. Untuk memilih antara pendekatan common effect dan fixed effect digunakan uji Chow. Uji tersebut dilakukan dengan melakukan uji statistik F. Di mana hipotesis nol $\left(\mathrm{H}_{0}\right)$ dilakukan dengan menggunakan nilai intersep dan kemiringan yang sama. Hipotesis yang digunakan adalah $\mathrm{H}_{0}$ : model mengikuti common effect dan $\mathrm{H}_{1}$ : model mengikuti fixed effect. Sedangkan untuk memilih antara pendekatan fixed effect dan random effect digunakan uji Hausman. Hipotesis yang digunakan adalah $\mathrm{H}_{0}$ : model mengikuti random effect dan $\mathrm{H}_{1}$ : model mengikuti fixed effect.

\section{HASIL DAN PEMBAHASAN}

\section{Hasil Uji Chow dan Hausman}

Untuk pemilihan model terbaik melalui Uji Chow dan Uji Hausman dapat dilihat pada Tabel 1. Hasil Uji Chow berfungsi untuk membandingkan model mana yang terbaik antara model PLS dan model fixed effect. Setelah itu dilanjutkan dengan uji Haustman Test untuk membandingkan model mana yang terbaik antara model fixed effect dan model random effect.

Tabel 1. Hasil Uji Chow dan Uji Hausman

\begin{tabular}{lrrrrrc}
\hline \multirow{2}{*}{ Sektor } & \multicolumn{3}{c}{ Fixed effect } & \multicolumn{3}{c}{ Random Effect } \\
\cline { 2 - 7 } & F Stat. & d.f. & Prob. & Chi-sq. Stat. & Df & Prob. \\
\hline Pertanian & 5516,87 & $(4,36)$ & 0,0000 & 4813,85 & 4 & 0,0000 \\
Manufaktur & 1727,16 & $(4,36)$ & 0,0000 & 4564,12 & 4 & 0,0000 \\
Pertambangan & 141,38 & $(4,36)$ & 0,0000 & 269,92 & 4 & 0,0000 \\
Konstruksi & 34,12 & $(4,36)$ & 0,0000 & 71,95 & 4 & 0,0000 \\
Jasa & 399,79 & $(4,36)$ & 0,0000 & 1328,31 & 4 & 0,0000 \\
\hline
\end{tabular}

Sumber: Eviews 6, data diolah

Nilai statistik uji F pada masingmasing sektor (pertanian, manufaktur, pertambangan, konstruksi dan jasa) menunjukkan nilai signifikansi $p$-value lebih kecil dari 5\%, sehingga model fixed effect pada kelima sektor merupakan model terbaik dibandingkan dengan PLS.

Melalui Uji Hausman, nilai pvalue pada uji chi-square pada sektor pertanian, pertambangan, manufaktur, konstruksi dan jasa lebih kecil dari 5\%. Hal tersebut dapat disimpulkan bahwa kelima sektor menggunakan model fixed effect.

\section{Hasil Estimasi Pengaruh FDI dan Kesempatan Kerja di ASEAN 5}

Hasil estimasi dampak FDI dan AFTA terhadap kesempatan kerja di ASEAN 5 dapat dilihat pada Tabel 2. Terdapat lima persamaan regresi yang terbagi menjadi sektor pertanian, manufaktur, pertambangan, konstruksi dan jasa. Dengan masing-masing 
koefisen variabel eksogen dengan nilai signifikansi alfa $(\alpha) 1 \%, 5 \%$ dan $10 \%$.

Pengujian kesesuaian model dapat dilakukan dengan menggunakan nilai F-statistik, t-statistik dan $\mathrm{R}^{2}$. Nilai F-statistik (Tabel 2) pada sektor pertanian, manufaktur, pertambangan, konstruksi dan jasa signifikan pada taraf nyata $1 \%$ menunjukkan bahwa masingmasing variabel secara bersama-sama berpengaruh nyata terhadap variabel tak bebas. Nilai t-statistik masing-masing variabel bebas menunjukkan nilai probabilitas yang signifikan sehingga model penduga sudah layak untuk menduga parameter yang ada di dalam fungsi.

Tabel 2 Hasil estimasi model Pengaruh FDI terhadap kesempatan kerja di lima sektor ekonomi negaranegara ASEAN-5 sesuai dengan hipotesis yang menunjukkan bahwa FDI sektor jasa berdampak positif dengan kesempatan kerja sektor jasa. Hal ini sesuai dengan hasil penelitian Jenkins (2006) yang menyatakan bahwa FDI sektor jasa memiliki dampak positif terhadap kesempatan kerja sektor tersebut. Hasil estimasi tersebut sesuai dengan hipotesis bahwa FDI berpengaruh positif terhadap kesempatan kerja sektoral. Sedangkan FDI pada empat sektor lainnya seperti pertanian, manufaktur, pertambangan dan konstruksi tidak memiliki pengaruh nyata terhadap kesempatan kerja sektor tersebut. Hasil estimasi pada empat sektor tersebut tidak sesuai dengan hipotesis namun sesuai dengan hasil penelitian Jude dan Silaghi (2015) yang menyatakan bahwa FDI tidak

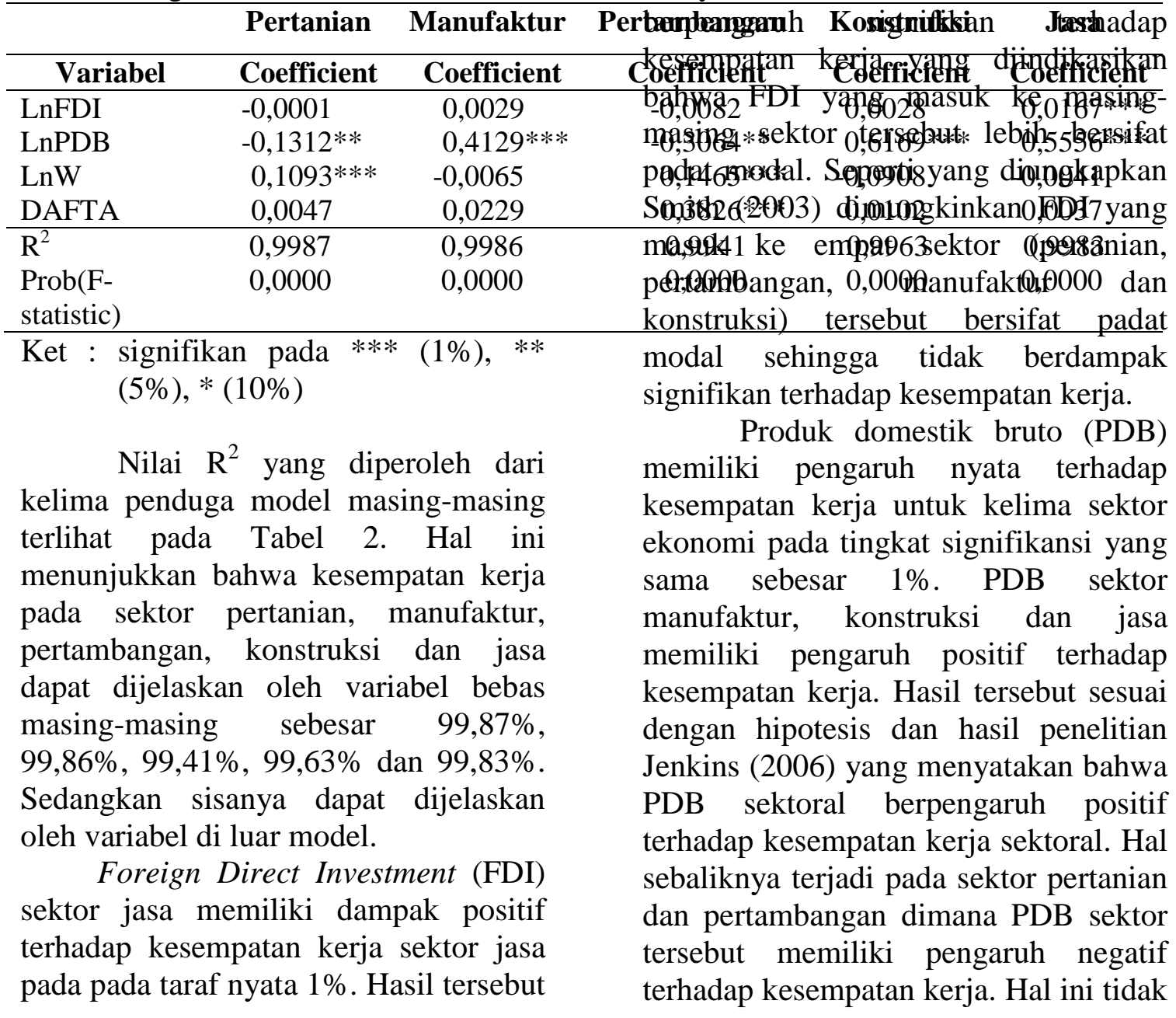


sesuai dengan hipotesis dan penelitian Jenkins (2006) yang menyatakan bahwa PDB sektoral berpengaruh positif terhadap kesempatan kerja sektoral. Diindikasikan bahwa sektor pertanian dan pertambangan mengalami efisiensi produksi dan mengalami peningkatan produktivitas dengan menyerap teknologi yang lebih maju (Smith, 2003).

Sementara tingkat upah sektor pertanian dan pertambangan berpengaruh positif terhadap kesempatan kerja di masing-masing sektor tersebut pada taraf nyata $1 \%$. Hasil estimasi tersebut tidak sesuai dengan hipotesis dan penelitian Jenkins (2006) yang menyatakan bahwa tingkat upah sektoral memiliki dampak negatif terhadap kesempatan kerja sektoral. Dapat disimpulkan bahwa masih memungkinkan untuk meningkatkan tingkat upah di kedua sektor tersebut untuk meningkatkan kesempatan kerja. Sementara pada tiga sektor lainnya (manufaktur, konstruksi dan jasa) berpengaruh negatif terhadap kesempatan kerja, namun tidak memiliki pengaruh yang signifikan. Pada ketiga sektor tersebut tidak memungkinkan lagi untuk meningkatkan tingkat upah karena akan berdampak pada menurunnya kesempatan kerja meskipun pengaruhnya sangat minim.

$$
\text { Variabel dummy AFTA }
$$

memiliki pengaruh positif terhadap kesempatan kerja pada sektor jasa pada taraf nyata $1 \%$. Pengaruh signifikan tersebut sesuai dengan hipotesis dan hasil penelitian Jude dan Silaghi (2015) yang menyatakan bahwa kerjasama perdagangan (AFTA) berdampak positif terhadap kesempatan kerja sektoral. Sementara pada sektor pertanian, manufaktur, konstruksi dan jasa tidak berpengaruh signifikan terhadap kesempatan kerja di masing-msaing sektor.

\section{SIMPULAN DAN SARAN}

\section{Simpulan}

Berdasarkan hasil penelitian yang diperoleh dari regresi data panel mengenai dampak Foreign Direct Investment dan AFTA terhadap kesempatan kerja sektoral dapat ditarik kesimpulan bahwa Foreign Direct Investment hanya memiliki dampak positif terhadap kesempatan kerja di sektor jasa. Namun tidak memiliki dampak yang signifikan pada sektor pertanian, pertambangan, manufaktur dan konstruksi. Peningkatan kesempatan kerja sektor manufaktur konstruksi dan jasa dipengaruhi secara nyata oleh variabel PDB. Sedangkan PDB sektor pertanian dan pertambangan memberikan dampak negatif terhadap kesempatan kerja sektor tersebut. Tingkat upah memiliki pengaruh positif terhadap kesempatan kerja di sektor pertanian dan pertambangan namun memiliki dampak negatif yang sangat minim terhadap kesempatan kerja di sektor manufaktur, konstruksi dan jasa. Kerjasama AFTA yang diberlakukan tahun 2010 memberikan perbedaan signifikan pada perkembangan kesempatan kerja di sektor manufaktur dan pertambangan. Dan kerjasama ini tidak memberikan perbedaan signifikan pada perkembangan kesempatan kerja di sektor pertanian, konstruksi dan jasa.

\section{Saran}

1. Pemerintah selaku regulator dapat mengefektifkan besarnya gelombang Foreign Direct Investment di kawasan Asia Tenggara untuk meningkatkan kesempatan kerja sektoral. Sektor jasa bisa dijadikan prioritas untuk dioptimalkan untuk 
mengembangkan kesempatan kerja. Karena FDI pada sektor tersebut memiliki dampak positif dan signifikan terhadap kesempatan kerja. Sektor manufaktur dan konstruksi dapat dijadikan alternatif pengembangan kesempatan kerja namun dampak yang diberikan di kedua sektor tersebut sangat minim. Untuk itu diperlukan aliran FDI masuk yang lebih besar lagi untuk mengembangkan kesempatan kerja di dua sektor tersebut. Sementara sektor pertambangan dan pertanian bukan menjadi pilihan tepat untuk meningkatkan kesempatan kerja di ASEAN 5.

2. Produk domestik bruto (PDB) pada sektor manufaktur, konstruksi dan jasa memiliki pengaruh positif terhadap kesempatan kerja di masing-masing sektor tersebut. Hal ini menjadi pilihan tepat bagi pemerintah untuk mengembangkan dan mengoptimalkan peran PDB di ketiga sektor tersebut untuk meningkatkan kesempatan kerja sektoral di ASEAN 5. Sedangkan PDB pada sektor pertanian dan pertambangan tidak menjadi pilihan tepat bagi pemerintah untuk meningkatkan kesempatan kerja sektoral di ASEAN 5.

3. Kebijakan untuk meningkatkan tingkat upah di sektor pertanian dan pertambangan masih memungkinkan dilakukan karena kenaikan tingkat upah pada kedua sektor tersebut berdampak positif terhadap kesempatan kerja. Sementara untuk sektor manufaktur, konstruksi dan jasa tidak memungkinkan lagi untuk meningkatkan tingkat upah karena dampak negatif yang ditimbulkan terhadap kesempatan kerja sektoral di ASEAN 5.

4. Kerjasama liberalisasi perdagangan melalui ASEAN Free Trade
Agreement (AFTA) dengan tujuan meningkatkan volume perdagangan antar negara ASEAN dan meningkatnya aliran masuk FDI diberlakukan pada tahun 2010. Kerjasama tersebut memiliki peran positif pada berkembangnya sektor manufaktur dan pertambangan sehingga memiliki pengaruh terhadap perkembangan kesempatan kerja sektoral di ASEAN 5.

\section{DAFTAR PUSTAKA}

Aitken BJ, Harrison AE. (1999). Do Domestic Firms Benefit from Direct Foreign Investment? Evidence from Venezuela. American Economic Review, American, Economic Association, Vol. 89(3): 605-618.

Alfaro L. 2003. Foreign Direct Investment and Growth: Does the Sector Matter? Harvard Business School.

Binger BR, Hofman E. 1988. Microeconomics with Calculus. Arizona; Harper Collins Publishers.

[ASEANSTAT] Association of Southeast Asian Nations Statistics. 2016. Foreign Direct Investment. Jakarta (ID). http://www.asean.org. [16 Desember 2015]

[BPS] Badan Pusat Statistik. 2016. Tabel Dinamis. Jakarta (ID). http://bps.go.id/. $\quad[10$ Januari 2016]

[BOT] Bank of Thailand. 2016. Key Economic Indicators. Bangkok (TH). https://www.bot.or.th. [25 Maret 2016]

[BSP] Bangko Sentral NG Pilipinas. 2016. Economic and Financial Statistics. Quezon City (PH). 
http://www.bsp.gov.ph.

Februari 2016]

[GSO] General Statistics Office of Vietnam. 2016. Statistical Data. Ha Noi (VN). https://www.gso.gov.vn. [11 April 2016]

Greenaway D., Hine R., Wright P. 1999. An empirical assessment of the impact of trade on employment in the United Kingdom. European Journal of Political Economy. Vol. 15: 485500.

Holland D, Benacek V, Gronicki M. 2000. The Determinants and Impact of Foreign Direct Investment in Central and Eastern Europe. Journal of United Nations. Vol.9: 163-212.

Hunya G, Geishecker I. 2005. Employment Effects of Foreign Direct Investment in Central and Eastern Europe. WIIW Research Report Vienna.

[ILOSTAT] ILO Database of Labor Statistics. 2016. Statistics and Database Browse by Country.Geneva $(\mathrm{CH})$. http://www.ilo.org. [24 Oktorber 2015]

Jenkins R. (2006)."Globalization, FDI and employment in Vietnam". Transnational Corporations. Vol. 15(1): 115-142.

Jude C, Silaghi MP. 2015. Employment effects of foreign direct investment. New evidence from Central and Eastern European Countries. International Economics CEPII Journal.

Konings J. 2004. The Employment Effect of Foreign Direct Investment. EIB Papers. Vol. 9(1): 87-108.

[LABORSTA] LABORSTA Internet. Statistics by Topic. Geneva $(\mathrm{CH})$. http://laborsta.ilo.org. [24 Oktober 2015]

[MYSIDC] Malaysia Department of Statistics. 2016. Malaysia Informative Data Centre. Putrajaya (MY). http://mysidc.statistics.gov. [7 Februari 2016]

Mencinger J. 2002. Does foreign direct investment always enhance economic growth? Kyclos 56 no.4.

Onaran O. 2007. Jobless Growth in the Central and East European Countries: A Country-Specific Panel Data Analysis of the Manufacturing Industry. Department of Economics Working Paper Series.(103).

[PSA] Philippine Statistics Authority. CountrySTAT Philippines. Quezon City (PH). http://psa.gov.ph/. [ 7 Februari 2016]

Radosevic S, Urmas V, Tomas $\mathrm{M}$. 2003. Foreign direct investment and its effects on employment in Central Europe. Transnational Corporations. 12(1).

Rama M. 2003. Globalization and Workers in Developing Countries. World Bank Policy Research Working Paper. 2958. (Washington, DC. World Bank)

[TAS] The ASEAN Secretariat. 2014. ASEAN Investment Report. Public Outreach and Civil Society Division.

Smith S. 2003. Labor Economics $2^{\text {nd }}$ Edition. London. Routledge Publishing.

[TNS] Thailand National Statistics Office. 2016. Table Compiled by NSO. Bangkok (TH). http://web.nso.go.th. [25 Maret 2016]

[UNCTAD] United Nations Conference on Trade and Development. 
Economic Trends. Geneva $(\mathrm{CH})$. http://unctad.org. [23 Oktober 2015]

[UNCTAD] United Nations Conference on Trade and Development. Investments. Geneva $(\mathrm{CH})$. http://unctad.org. [23 Oktober 2015]
Waldkirch A. 2008. The Effect of Foreign Direct Investment in Mexico since NAFTA. Muenchen (DE). Munich Personal RePEc Archive Paper. (7975).

[WB] World Bank. 2016. World Development Indicator. Washington DC (US). http://data.worldbank.org. [23 Oktober 2015] 